\title{
THE INFLUENCE OF THE ENVIRONMENT ON THE SIZE OF EXPECTED CLASSES.
}

T. H. MORGAN AND SABRA COLBY TICE.

In crosses in which rudimentary wings are involved, it has been apparent, since this race was first bred, that the classes containing rudimentary wings often run far behind expectation. The experiments made clear that the character rudimentary wings is a Mendelian recessive and is sex-linked. The deficiencies that appeared were assigned to viability of these flies. We have found meanwhile for other stocks that by breeding pairs of flies in large bottles, with an abundance of food, kept in good condition, there was a very marked increase in number of those classes that are deficient in number if many flies are bred in small bottles, or even in large bottles if so many parents are used that crowding of the larvae takes place. It was determined, therefore, to repeat the experiments with rudimentary wings under the most favorable conditions that our experience had made known to us. In order to avoid the possible criticism that the stock might have changed, a control culture en masse was again made in which crowding took place.

Results similar to these with rudimentary wings had also come up in crosses in which a new mutant, "strap wing" was involved. This factor is not sex linked, but belongs to our second group. Similar experiments were carried out with this stock.

\section{The Viability of the Rudimentary Winged Race.}

In a paper in Science, I9I I, ${ }^{1}$ an $\mathrm{F}_{2}$ count is given in which 5,850 long-winged flies ( $\sigma^{7}$ and $\%$ ) and 83 rudimentary-winged males are recorded. The expectation is that of these 5,850 flies one third should be long-winged males, or I,950. This number is also the expectation for the rudimentary-winged males. Instead of $\mathbf{I}, 950$ there are only 83 males or $\mathrm{I} / 23$ the expected number.

1 Science, Vol. XXXIII., March 3I, IgII. 
The $F_{1}$ generation of the reciprocal cross was published in Science, I9I2. ${ }^{1}$ The rudimentary-winged female bred to a longwinged male gave $38 \mathrm{I}$ long-winged daughters and only 3 rudimentary-winged sons where equality was expected. Whether the lack of sons here is due entirely to viability, or to other conditions as well cannot be stated.

In a very brief paper in $I 9 I^{2}{ }^{2}$ some other data were given that showed the rudimentary classes running behind expectation. These data were corrected and expanded in another paper, ${ }^{3}$ to which reference may now be made. An $\mathrm{F}_{2}$ count is given there, that is an extension of the data published in the first paper referred to above. There are 14,309 long-winged grandchildren $\left(\sigma^{7} \sigma^{7}\right.$ and $\circ$ o $)$ and II5 males with rudimentary wings. The expectation here is that one third of 14,309 or 4,769 flies should have rudimentary wings. The entire number is I I 5 , or only I/4I of the expected number.

There is an $F_{1}$ count of the reciprocal cross when 68 long-winged daughters and 3 rudimentary-winged sons appear. This ratio is not lower than that given above, and may safely be ascribed to viability. In the $F_{2}$ count of the same combination the following classes and numbers were realized:

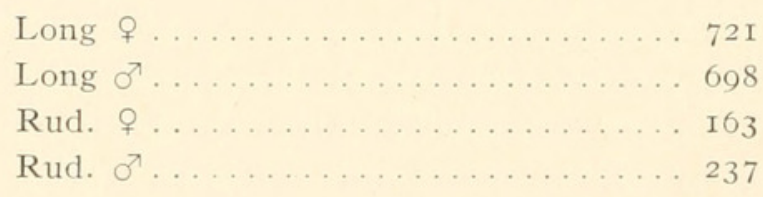

The expectation is for equal numbers. The rudimentary males, while far behind expectation, are not so far behind as in other crosses cited, which is due to better treatment. This same statement applies to the remaining data of the I9I2 paper for, at that time realizing more fully the influence of the environment on viability larger bottles with more food were used. Since most of the data involves miniature wings it is not cited here.

In the new experiments rudimentary-winged males were bred to long-winged (wild) females; and long-winged daughters and sons obtained. The daughters were then back-crossed to rudimentary males either in pairs or en masse. When bred en masse

${ }^{1}$ Science, Vol. XXXIV., March 22, I9I2.

${ }^{2}$ Proc. Soc. Exp. Biol. and Medicine, VIII., February, I9I I.

${ }^{3}$ Zeit. f. induktive Abstammungs und Vererbunglehre, VII., I9I 2. 
the following offspring were obtained. The expectation is for equality in all four classes:

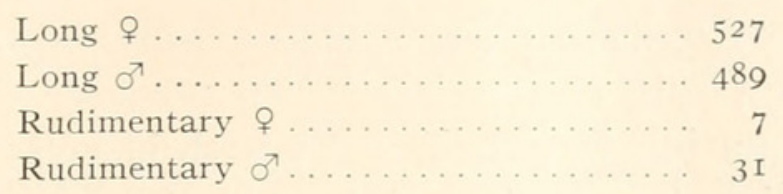

There is an enormous deficit in the classes of rudimentary flies. Instead of equality there are only $\mathrm{I} / 27$ as many as expected.

When on the other hand the $\mathrm{F}_{1}$ females were back-crossed in pairs the following totals were obtained:

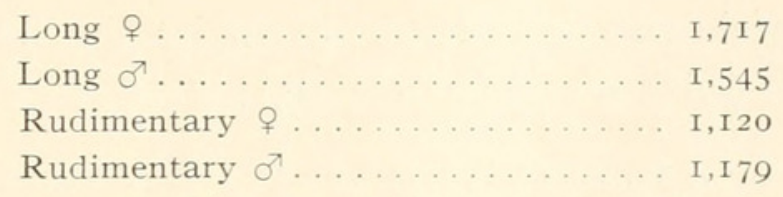

There is an approach to equality in the last case ( $1: .7)$, and, in consequence, the contrast with the preceding data is striking. For purposes of more detailed comparison the data for the two mass cultures and for the 20 pairs is given:

TABLE I.

BACK-CROSS PAIRS.

\begin{tabular}{|c|c|c|c|c|}
\hline No. & Long $q$. & Long $\sigma^{\top}$. & Rudimentary $\odot$. & Rudimentary $\sigma^{x}$. \\
\hline 7 & I33 & I I 7 & 94 & 102 \\
\hline 8 & 59 & 43 & 55 & 47 \\
\hline 9 & 107 & I I 4 & 67 & 66 \\
\hline IO & 70 & 55 & 46 & 64 \\
\hline I I & 62 & 60 & 53 & 36 \\
\hline I 2 & 49 & 36 & $5 \mathrm{I}$ & $4 \mathrm{I}$ \\
\hline I3 & 86 & 76 & $3 \mathrm{I}$ & 43 \\
\hline I 4 & I35 & IOI & $6 \mathrm{I}$ & I 04 \\
\hline I 5 & I07 & IO2 & $6 \mathrm{I}$ & 79 \\
\hline I6 & . 67 & 44 & 60 & 54 \\
\hline I 7 & I 6 & 107 & 73 & 70 \\
\hline I 8 & 92 & 80 & 72 & 68 \\
\hline I9 & 87 & 77 & 84 & 53 \\
\hline 20 & I6 & I4 & I 2 & 6 \\
\hline $2 \mathrm{I}$ & 78 & IOI & 73 & 72 \\
\hline 22 & 83 & 60 & 44 & 50 \\
\hline 23 & 88 & $8 I$ & 62 & $9 \mathrm{I}$ \\
\hline 24 & 52 & 49 & 35 & 37 \\
\hline 25 & 95 & I0O & 56 & 65 \\
\hline 26 & I 35 & I 28 & 30 & $3 \mathrm{I}$ \\
\hline al. . & I, 717 & $\mathrm{I}, 545$ & $\mathrm{I}, \mathrm{I} 2 \mathrm{O}$ & I, I 79 \\
\hline
\end{tabular}


Back-Cross En Masse.

\begin{tabular}{c|c|c|c|c}
\hline $\begin{array}{c}28 \\
29\end{array}$ & 248 & 235 & 4 & I 4 \\
279 & 254 & 3 & I 7 \\
\hline Total . . . & 527 & 489 & 7 & 3 I \\
\hline
\end{tabular}

This same mating was again made both in mass and in pairs. The expectation is equality of long and rudimentary wings. The mass cultures gave:

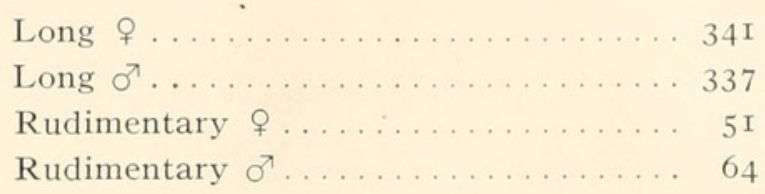

When the experiment was made with pairs the following totals were obtained, (with a ratio of I. : .63):

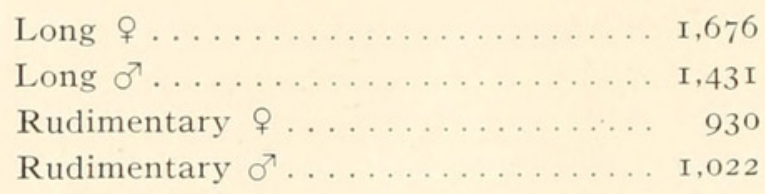

For detailed comparison the counts of the two mass cultures and of the 29 pairs taken separately are given in Table II.

TABle II.

BACK-CROSS PAIRS.

\begin{tabular}{|c|c|c|c|c|}
\hline No. & Long 9 . & Long ơ & Rudimentary $\circ$. & Rudimentary $\sigma^{7}$. \\
\hline $3 \mathrm{I}$ & I6I & 122 & I08 & I 54 \\
\hline 32 & I 5 & 7 & 5 & 4 \\
\hline 33 & I 54 & I 2 I & 27 & 30 \\
\hline 34 & 82 & IO3 & 38 & 66 \\
\hline 35 & IO3 & $8 \mathrm{I}$ & I I & I3 \\
\hline 36 & I 43 & 74 & I 2 & 42 \\
\hline 37 & 86 & 84 & 62 & 49 \\
\hline $3^{8}$ & 59 & 79 & $5 \mathrm{I}$ & 57 \\
\hline 39 & I 23 & 98 & 67 & $6 I$ \\
\hline 40 & I 64 & I 42 & 70 & 85 \\
\hline $4 \mathrm{I}$ & 63 & 59 & $7 \mathrm{I}$ & 54 \\
\hline 42 & 72 & 45 & 47 & 42 \\
\hline 43 & 56 & 65 & 55 & 55 \\
\hline 44 & 47 & $5 \mathrm{I}$ & 47 & 46 \\
\hline 45 & 45 & 37 & 34 & 25 \\
\hline 46 & 93 & 64 & 42 & 47 \\
\hline 47 & 45 & 50 & 46 & 33 \\
\hline 48 & 63 & 47 & 44 & 55 \\
\hline 49 & 59 & 45 & 52 & 65 \\
\hline 50 & 63 & 57 & $4 \mathrm{I}$ & 39 \\
\hline al. . & I, 676 & $\mathrm{I}, 43 \mathrm{I}$ & 930 & $\mathrm{I}, 022$ \\
\hline
\end{tabular}


Back-cross En Masse.

\begin{tabular}{|c|c|c|c|c|}
\hline $\begin{array}{l}5 \mathrm{I} \\
52\end{array}$ & $\begin{array}{l}\text { I } 54 \\
\text { I } 87\end{array}$ & $\begin{array}{l}135 \\
202\end{array}$ & $\begin{array}{l}\text { I } 8 \\
33\end{array}$ & $\begin{array}{l}19 \\
45\end{array}$ \\
\hline Total. & $34 \mathrm{I}$ & 337 & $5 \mathrm{I}$ & 64 \\
\hline
\end{tabular}

Since rudimentary females are sterile with rudimentary males the stock of rudimentary wings is maintained by breeding rudimentary males to heterozygous, long-winged females.

The Viability of the Strap-wing Race.

The peculiarities of structure and inheritance of this mutant will be described in another place. The stock contained "beading" and overlaps in appearance the vestigial wing. The "beaded" flies that appear in $\mathrm{F}_{2}$ are classified with "normal" or long wing, those with vestigial-like wings are counted in with "strap." Strap bred to wild stock gives sons and daughters with long wings. These bred en masse during August gave the following results in eleven cultures. About six to ten $F_{1}$ flies were used in each culture in a medium sized bottle, and the food conditions were made as favorable as possible.

\begin{tabular}{|c|c|c|c|}
\hline & Normal. & Strap. & Ratio. \\
\hline I. & 224 & 59 & I : 3.8 \\
\hline 2. & 236 & 63 & I $: 3.7$ \\
\hline 3. & $47 \mathrm{I}$ ( +39 curved $)$ & 28 & $I: 17.0$ \\
\hline 4. & 216 & 45 & I : 4.8 \\
\hline 5 . & I03 & II & I : 9.3 \\
\hline 6. & 277 & 24 & I $:$ II.5 \\
\hline 7. & I62 & I4 & I $:$ II. 6 \\
\hline 8. & 464 & 23 & $I: 20.1$ \\
\hline 9. & 494 & 82 & I : 6.2 \\
\hline Iо. & 288 & 44 & I : 6.5 \\
\hline II. & I64 & 34 & I : 4.8 \\
\hline Total. & $3,099(+39)$ & 427 & I : 7.2 \\
\hline
\end{tabular}

The ratios range from $\mathrm{I}: 3 \cdot 7$, to I $: 20 . \mathrm{I}$. In order to compare these results with matings in pairs, fifteen pairs were mated. After ten days the parents were placed in a new bottle with fresh food and in some cases they were carried to a third bottle. The results are given in the next table (III.).

The results from pairs approximate more nearly to expectation $(\mathrm{I}: 3)$; the totals give a ratio of $\mathrm{I}: 3.57$. The individual lots 
TABLE III.

\begin{tabular}{|c|c|c|c|c|c|c|c|c|c|c|c|c|c|c|c|}
\hline \multirow{3}{*}{ No. } & \multicolumn{5}{|c|}{ Brood I. } & \multicolumn{5}{|c|}{ Brood II. } & \multicolumn{5}{|c|}{ Brood IIl. } \\
\hline & \multicolumn{2}{|c|}{ Normal. } & \multicolumn{2}{|c|}{ Strap. } & \multirow{2}{*}{$\begin{array}{l}\text { Ratio } \\
\text { to } \mathrm{I} \text {. }\end{array}$} & \multicolumn{2}{|c|}{ Normal. } & \multicolumn{2}{|c|}{ Strap. } & \multirow{2}{*}{$\begin{array}{l}\text { Ratio } \\
\text { to } \mathrm{I} .\end{array}$} & \multicolumn{2}{|c|}{ Normal. } & \multicolumn{2}{|c|}{ Strap. } & \multirow{2}{*}{$\begin{array}{l}\text { Ratio } \\
\text { to } \mathbf{r}\end{array}$} \\
\hline & ㅇ. & $\sigma^{7}$ & 우 & $\sigma^{7}$ & & ㅇ & $\sigma^{7}$ & ㅇ & $\sigma^{7}$ & & क & $\sigma^{7}$ & ㅇ & व & \\
\hline I & 97 & 89 & 27 & I 7 & 4.2 & 218 & I99 & 60 & 47 & 3.9 & - & - & - & - & - \\
\hline 2 & I 12 & I 16 & 24 & 20 & 5.2 & I 48 & I 4 I & 23 & 26 & 5.9 & 48 & 44 & I6 & I 4 & 3.1 \\
\hline 3 & 90 & 76 & I3 & I 2 & 6.6 & 88 & 88 & 8 & 5 & I 3.5 & - & - & - & - & - \\
\hline 4 & I I 7 & IOI & 37 & I 4 & $4 \cdot 3$ & 99 & I30 & 38 & 28 & $3 \cdot 5$ & 25 & $4 \mathrm{I}$ & IO & 16 & 2.4 \\
\hline 5 & 73 & 63 & 24 & $3 \mathrm{I}$ & 2.5 & 80 & 88 & 34 & 30 & 2.6 & 7 & 3 & I & I & - \\
\hline 6 & 79 & 90 & 23 & 26 & $3 \cdot 5$ & I 19 & IOO & 30 & 24 & 4. I & IO & I 4 & 2 & 5 & - \\
\hline 7 & 105 & 86 & $3 I$ & 27 & $3 \cdot 3$ & I $2 \mathrm{I}$ & I I 5 & 27 & 37 & 3.7 & 50 & 59 & I 2 & 23 & $3 . I$ \\
\hline 8 & 94 & $9 \mathrm{I}$ & 32 & 22 & 3.4 & I 20 & I I 3 & 39 & 36 & 3.1 & 24 & 37 & Io & 6 & 3.8 \\
\hline 9 & 95 & 87 & I9 & $3 \mathrm{I}$ & 3.6 & IOI & I06 & 29 & 29 & 3.6 & 59 & 42 & I 7 & 27 & 2.3 \\
\hline IO & 72 & 60 & $3 \mathrm{I}$ & 26 & 2.3 & 46 & 59 & 22 & 20 & 2.5 & 5 & - & I & - & - \\
\hline I I & 66 & 63 & I 2 & 22 & 3.8 & 57 & 36 & 5 & 7 & 7.7 & - & - & - & - & - \\
\hline I 2 & 79 & 68 & 27 & 38 & 2.3 & 77 & 77 & 28 & 24 & 3.0 & 3 & 3 & I & - & - \\
\hline I3 & 79 & 65 & 26 & I 5 & $3 \cdot 5$ & 54 & 62 & I 7 & I 8 & $3 \cdot 3$ & 37 & 29 & IO & 5 & 4.4 \\
\hline I 4 & 85 & 80 & 28 & 26 & 3.1 & 78 & 90 & 22 & $2 \mathrm{I}$ & 3.9 & 32 & 34 & I I & 7 & 3.8 \\
\hline \multirow[t]{2}{*}{ I 5} & 62 & $6 \mathrm{I}$ & I 4 & I 5 & $4 . I$ & 63 & 53 & $2 \mathrm{I}$ & 26 & 2.5 & 30 & 17 & 7 & 7 & $3 \cdot 4$ \\
\hline & I, 305 & I, I 96 & 368 & 342 & 2.52 & $\mathrm{I}, 479$ & I, 457 & 403 & 378 & 3.75 & 330 & 323 & 08 & I I I & 3.12 \\
\hline
\end{tabular}

are worthy of inspection. The ratios run more evenly and range from I $: 2.3$ to $\mathrm{I}: 7.7$ with one exceptionally high at I : I3.5. The counts from day to day (not recorded here) show that the $F_{2}$ strap-winged flies hatch later than the flies with normal wings, so that as the cultures run out, the relative number of strapwing flies increases, and unless the cultures are exhausted when the count stops there will be a deficiency of strap-wing flies. An attempt was made to run the cultures to a finish, although this cannot always be done. If the cultures dry up, a disproportionately large number of strap-winged flies will be destroyed, and this will account in part for the deficiency in this class. These results are not affected by the age of the parents, as shown by comparison of the ratios in the totals for the second $(\mathrm{I}: 3.75)$ and third $(\mathrm{I}: 3 . \mathrm{I2})$ broods with that of the first $\left(\mathrm{I}: 3.5^{2}\right)$.

The above pairs were mated in November and December, I9I3. In order to make a more exact comparison, a few mass cultures were made in December from the same stocks. The results are shown in the next table (IV.).

In addition to the preceding data there were other crosses of strap male by wild female that had been made nine months 
TABLE IV.

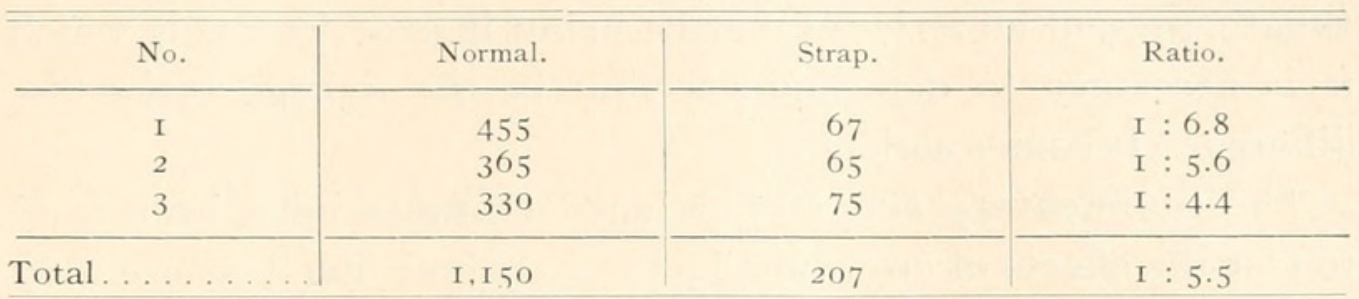

before those recorded above. In these earlier experiments in mass cultures no attempt was made to avoid crowding through use of too many parents, although the bottles were otherwise maintained in good condition. The following $F_{2}$ counts were made:

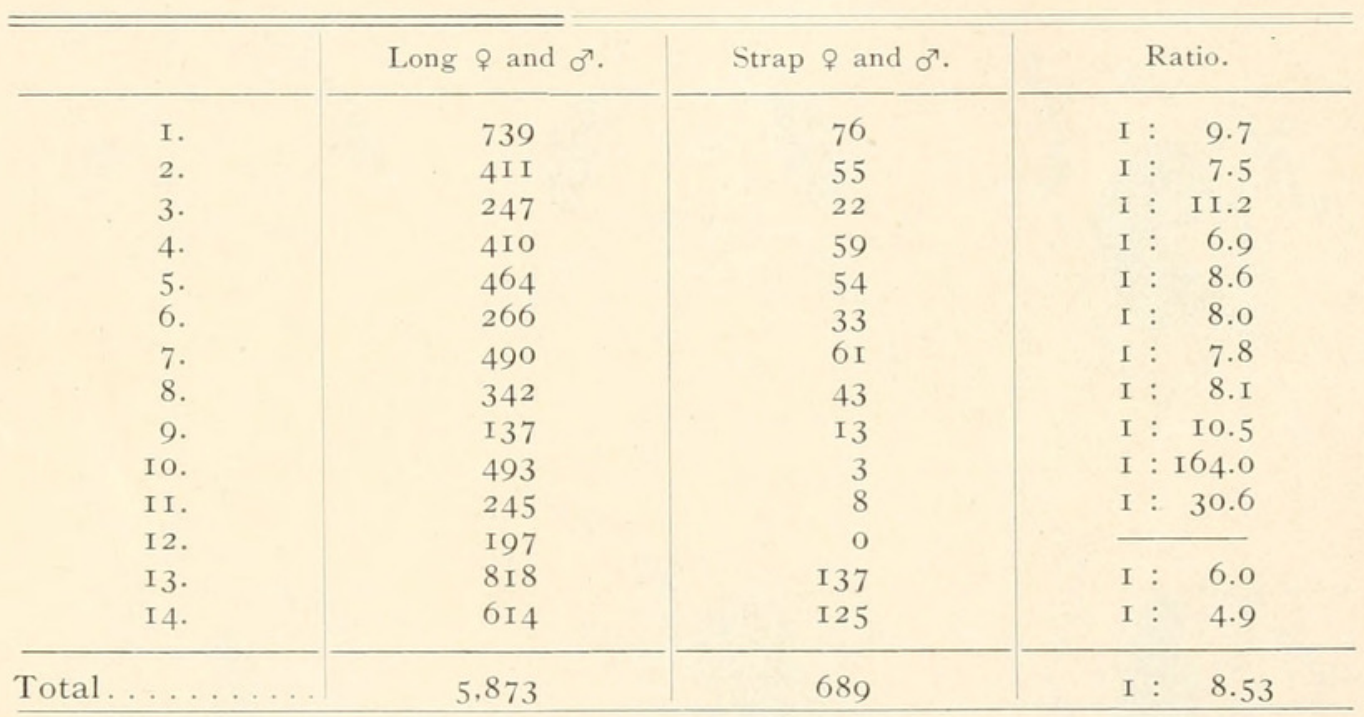

Whether the two very high ratios under Io and I 2 should be included may be questioned. It is possible though not probable that contamination took place. Excluding these the ratios vary from I $: 4.9$ to $I: 30.6$.

\section{Conclusions.}

The experiments show that under unfavorable conditions due to crowding the mutant forms, rudimentary wings and strap wings, run behind expectation. That the result is due to crowding is shown when cultures of sister individuals are made in pairs with abundant room and food. There is then a closer, and in some cultures a complete agreement with expectation. In experiments in which it is only necessary to show whether a character is recessive or dominant, and whether it is, or is not 
linked to other characters these deficient ratios, while unfortunate, present no serious difficulties, but in experiments in which it is necessary to determine accurately the linkage ratios the difference becomes serious.

The rudimentary and strap-winged mutants have been used to test the effects of crowding due to mass breeding, because they have been found to show such effects more than any other stocks. In the case of other mutants that give, even in mass cultures, nearly the theoretical values, the method which we now generally employ of breeding by pairs in large culture bottles with plenty of food eliminates almost entirely disturbances due to viability. 


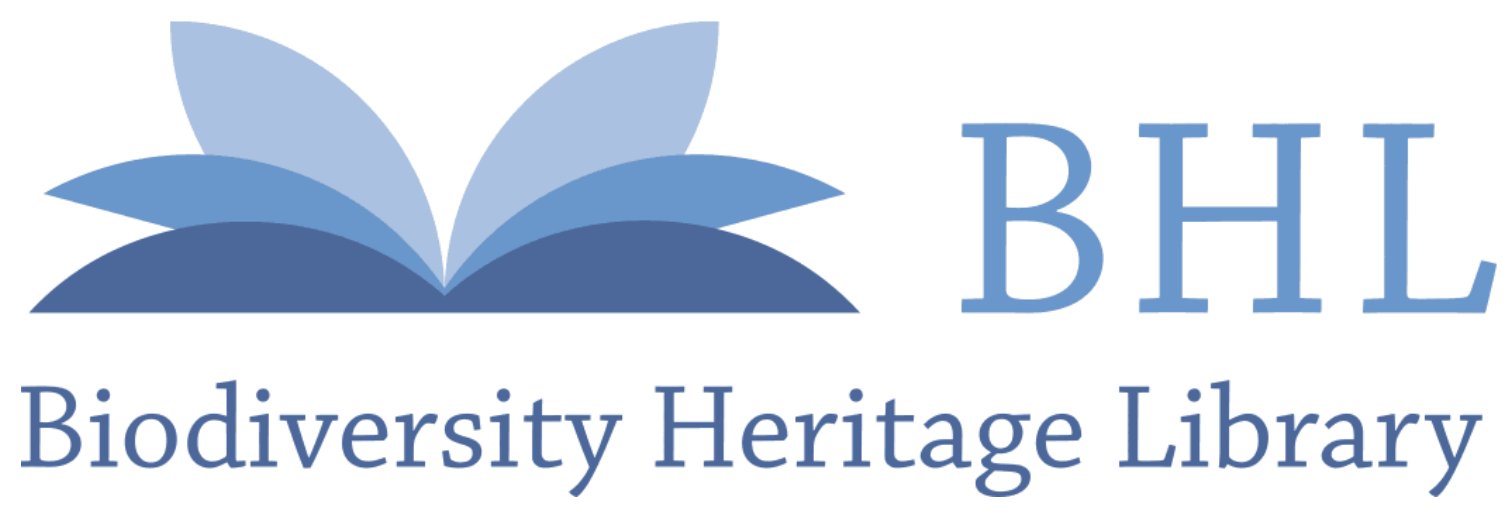

Morgan, Thomas Hunt and Tice, Sabra Colby. 1914. "THE INFLUENCE OF THE ENVIRONMENT ON THE SIZE OF EXPECTED CLASSES." The Biological bulletin 26, 213-220. https://doi.org/10.2307/1536195.

View This Item Online: https://www.biodiversitylibrary.org/item/17128

DOI: https://doi.org/10.2307/1536195

Permalink: https://www.biodiversitylibrary.org/partpdf/26088

\section{Holding Institution}

MBLWHOI Library

Sponsored by

MBLWHOI Library

\section{Copyright \& Reuse}

Copyright Status: NOT_IN_COPYRIGHT

This document was created from content at the Biodiversity Heritage Library, the world's largest open access digital library for biodiversity literature and archives. Visit BHL at https://www.biodiversitylibrary.org. 